\title{
Control of oocyte maturation, sperm activation and spawning in two lugworm species: Arenicola marina and $A$. defodiens
}

\author{
G. J. Watson ${ }^{1, *}$, P. S. Cadman ${ }^{2}$, L. A. Paterson ${ }^{1}$, M. G. Bentley ${ }^{1}$, M. F. Auckland ${ }^{1}$ \\ ${ }^{1}$ Gatty Marine Laboratory, School of Environmental and Evolutionary Biology, University of St Andrews, St Andrews, \\ Fife KY16 8LB, Scotland, UK
}

${ }^{2}$ Faculty of Agriculture and Biological Sciences, Department of Marine Sciences and Coastal Management, Ridley Building, University of Newcastle, Newcastle-upon-Tyne NE1 7RU, England, UK

\begin{abstract}
In addition to the morphological differences between Arenicola defodiens (Cadman and Nelson-Smith, 1993) and Arenicola marina (L.) this study demonstrates clear differences in the reproductive biology, timing of reproduction at a population level, and endocrine control of reproduction in females. Fecundity is significantly higher in females of $A$. marina and the mean diameter of their fully grown oocytes is also significantly larger than in $A$. defodiens. The timing of reproduction at a population level is also different with $A$. defodiens spawning approximately 1 to 2 mo later than sympatric $A$. marina. In vitro and in vivo experiments have established fundamental differences as well as similarities in the hormonal control of reproduction of both sexes between the 2 species. Male A. defodiens can be induced to spawn by the injection of $8,11,14$-eicosatrienoic acid into the coelomic cavity, putatively shown to be the natural sperm maturation factor and spawning hormone in $A$. marina. In females, injection of female prostomial homogenate from either species into the coelomic cavity induces oocyte maturation and subsequent spawning in both species. However, oocytes of $A$. marina, whilst maturing in the presence of CMF (Coelomic Maturation Factor) in vitro, do not mature in the presence of prostomial homogenate of either species, whereas $A$. defodiens oocytes do. In A. marina, oocyte maturation and subsequent spawning is under the control of 2 hormones: (1) a substance from the prostomium, Prostomial Maturation Hormone (PMH), which induces the production of (2) CMF which acts on the oocyte. In $A$. defodiens, we show that only PMH is required for oocyte maturation and spawning. The in vitro induction of oocyte maturation in A. marina, by a variety of chemicals and treatments that have already been shown to induce maturation in $A$. defodiens and species from other phyla, was investigated. None of the chemicals and treatments tested induces maturation in A. marina or A. defodiens oocytes.
\end{abstract}

KEY WORDS: Arenicola manina. A defodiens CMF - Hormone Oocyte maturation Polychaeta Spawning $\cdot$ Sperm activation

\section{INTRODUCTION}

Gamble \& Ashworth (1898) were the first to distinguish 2 'varieties' of Arenicola marina which they termed the 'littoral' and 'laminarian' varieties, but this distinction was subsequently lost from the literature. The recent work of Cadman \& Nelson-Smith (1990,

·E-rnail: gjw@st-andrews.ac.uk
1993) and Cadman (1997) has shown, through the examination of a number of morphological, ecological and genetic characteristics, that this distinction was valid, and consequently the 'laminarian' variety has been classed as a separate species, Arenicola defodiens (Cadman \& Nelson-Smith).

Arenicola marina and $A$. defodiens are dioecious, annually iteroparous species. A. marina has a wide distribution, being found in sandy beaches and estuaries across Northern Europe (Wells 1963, Beukema \& de 
Vlas 1979, Farke \& Berghuis 1979, Farke et al. 1979). The distribution of $A$. defodiens is, however, largely unknown, with only the original work of Gamble \& Ashworth (1898) and a recent study by Cadman (1997) having examined its distribution and abundance. In both South Wales (UK) and several sites on the Northumberland coast (UK), locations where A. defodiens only are present are relatively common, but there are also a number of sites where both species exist sympatrically. The sites investigated where only A. defodiens are present were more likely to be of an exposed nature than sites where only $A$. marina occur. $A$. defodiens was also absent from all the estuaries investigated, in contrast to $A$. marina, densities of which are often at their highest in estuaries. Where both species coexist, $A$. defodiens are usually found at a lower position on the shore (in relation to tidal height) than sympatric A. marina (Cadman 1997).

The hormonal control of reproduction and spawning in Arenicola marina is now one of the most comprehensively studied systems in polychaetes. In males, the fatty acid 8,11,14-eicosatrienoic acid has been putatively identified as the Sperm Maturation Factor (SMF) and spawning hormone found in the prostomium (Bentley 1985, Bentley et al. 1990, Pacey \& Bentley 1992a, b, Bentley \& Hardege 1996). In females, oocyte maturation involves the progression from late prophase of the first meiosis to metaphase following germinal vesicle breakdown (GVBD) (Howie 1961). Oocyte maturation and subsequent spawning are induced by a hormone from the prostomium (Howie 1961, 1963, 1966, Pacey \& Bentley 1992a). Recent work has shown that oocyte maturation and subsequent spawning requires 2 steps: production of the substance from the prostomium, termed the Prostomium Maturation Hormone (PMH), which induces the production of a second substance, the Coelomic Maturation Factor (CMF), which is detectable in the coelomic fluid prior to spawning (Watson \& Bentley 1997, 1998a, b). Oocytes can only be matured in vitro in the presence of $\mathrm{CMF}$ and will not mature when incubated with $\mathrm{PMH}$ (Watson \& Bentley 1997).

The work by Meijer \& Durchon (1977) and Meijer $(1979 a, b, 1980)$ on what was originally identified as Arenicola marina, but is now considered to be $A$. defodiens ( $A$. marina $[\mathrm{sic}]=A$. defodiens) and so for ease of writing will be referred to in this paper as $A$. defodiens, are the only investigations into gamete maturation and spawning in this species. In females, spawning can be induced by the injection of female prostomial homogenate; however, oocytes will undergo maturation in vitro when incubated in only prostomial homogenate, suggesting a single step mechanism. Meijer (1980) also showed that calcium plays an important role in oocyte maturation as a number of chemicals affecting calcium induced maturation in vitro. In males, induction of spawning and the activation of sperm in vitro were induced with male prostomial homogenate, suggesting similarities with A. marina.

The collection of both species from a number of populations around the UK that spawn at different times enabled the reproductive biology of both species to be investigated simultaneously. This paper examines differences and similarities between the 2 species in their control of reproduction and investigates the differences in reproductive morphology and timing of reproduction at a number of sites where both species are found sympatrically. Experimentally, we have investigated the role of $8,11,14$-eicosatrienoic acid in the control of spawning in male Arenicola defodiens. In females, reciprocal experiments examine the role of PMH found within each species' prostomial homogenate in inducing spawning in the other. Focusing on the oocytes of both species, the role of CMF in inducing maturation in vitro in comparison to prostomial homogenate from both species was also assessed. The chemical pathways involved in oocyte maturation within oocytes were also examined through a number of different treatments, and compared and contrasted to previous results for $A$. defodiens (Meijer 1980) and other systems from other phyla.

\section{MATERIALS AND METHODS}

Collection of mature specimens. The majority of sexually mature Arenicola marina were collected as described previously (Watson \& Bentley 1997). The remainder of the $A$. marina and all the $A$. defodiens were also collected as described previously, but at varying times prior to the spawning of the population and were then maintained in culture facilities at Seabait Ltd (Ashington, Northumberland, UK) under ambient conditions until required. In all experiments, only specimens with a homogenous population of fully developed gametes were used.

Observations and investigations of oogenesis, female fecundity and spawning in the field. Oocyte size frequency measurements were taken from mature females of 7 Arenicola marina and $5 \mathrm{~A}$. defodiens collected from Hauxley Haven (Northumberland, UK) where both species exist sympatrically. Data for $A$. marina and $A$. defodiens were from specimens $C o l-$ lected on 25 October and 20 December 1995 respectively. Both dates were just prior to the spawning of each population (see 'Results'). For the oocyte size frequency data, samples of coelomic fluid were removed from each specimen and the diameters of approximately 50 oocytes were measured. Fecundity of 
females of both species taken from ongoing cultures at Seabait Ltd was measured by taking replicate subsamples of spawned oocytes and recording the wet weight of each specimen. Observations on the spawning of populations in the field were obtained whilst collecting specimens for experiments and inferred from the spontaneous spawning of specimens within the laboratory.

Induction of spawning. Three sets of spawning experiments were performed. All injection techniques, production of prostomial homogenate and the experimental design were as described previously (Pacey \& Bentley 1992a, Watson \& Bentley 1997). All specimens injected with prostomial homogenate were injected to give a final concentration equivalent to 1 prostomium per specimen.

For the first experiment (performed in 1997), 18 male Arenicola defodiens and 40 male $A$. marina were divided into 5 treatment groups. Six $A$. defodiens and 20 A. marina (positive controls) were each injected with 8,11,14-eicosatrienoic acid to give a final concentration of $13 \mu \mathrm{g} \mathrm{g}^{-1}$ body mass. As a further positive control, $6 \mathrm{~A}$. defodiens were injected with male $A$. defodiens prostomial homogenate. As a negative control, 6 A. defodiens and 20 A. marina were each injected with $200 \mu$ twice filtered seawater (TFSW). All specimens were left for $12 \mathrm{~h}$ at $10^{\circ} \mathrm{C}$ before being assessed for spawning.

The second experiment was performed in 1993 with 24 female Arenicola marina divided equally into 3 treatment groups. Individuals in the first group were each injected with female $A$. marina prostomial homogenate, and those in the second group with female $A$. defodiens prostomial homogenate. Individuals in the final treatment group were each injected with $200 \mu \mathrm{l}$ TFSW as a negative control. All specimens were left for $12 \mathrm{~h}$ at $10^{\circ} \mathrm{C}$ before being assessed for the presence of spawned oocytes.

For the third experiment (performed in 1997) 15 female Arenicola defodiens and 17 female A. marina were divided into 3 treatment groups. In the first treatment group, $5 \mathrm{~A}$. defodiens and $6 \mathrm{~A}$. marina were each injected with female $A$. marina prostomial homogenate. In the second group, $5 \mathrm{~A}$. defodiens and $5 \mathrm{~A}$. marina were each injected with female $A$. defodiens prostomial homogenate. In the final treatment group 5 $A$. defodiens and 6 A. marina were each injected with $200 \mu \mathrm{l}$ TFSW as a negative control. All specimens were left for $12 \mathrm{~h}$ at $10^{\circ} \mathrm{C}$ before being assessed for the presence of spawned oocytes.

In vitro maturation of oocytes. Oocytes of both species were incubated in coelomic fluid containing CMF from 5 females and prostomial homogenate of Arenicola marina and $A$. defodiens at respective concentrations of $0.2,1,10$ and $0.2,1$ and 5 prostomial $\mathrm{ml}^{-1}$.
Oocytes of both species were also incubated in TFSW as a negative control. Prostomial homogenate for both species was produced using the same technique as described previously for $A$. marina, as was the induction of CMF production in the $A$. marina females (Watson \& Bentley 1997). In all experiments, 5 pl of oocytes from each of 2 females of each species was incubated in $50 \mu \mathrm{l}$ of the test solution and incubated for $3 \mathrm{~h}$ at $10^{\circ} \mathrm{C}$ before assaying for maturation. Oocyte maturation in both species was assessed as described previously (Watson \& Bentley 1997)

Chemical induction of oocyte maturation in Arenicola marina. Five $\mu l$ of pooled oocytes (from a number of oocyte donors) was added to $1 \mathrm{ml}$ of each treatment at each concentration and to the controls. All incubations were performed at $10^{\circ} \mathrm{C}$ in the dark. Oocytes were sampled after 2 and $4 \mathrm{~h}$ and then assessed for maturation as described above. Artificial seawater (ASW), made up according to Baloun \& Morse (1984), was used for all chemical dilutions. All chemicals were dissolved directly in ASW except for ionophore A23187 and arachidonic acid which were first dissolved in ethanol and then subsequently diluted in ASW to give a final ethanol concentration of $1 \%$.

Chemicals and treatments tested for maturation inducing activity: Oocytes were incubated in coelomic fluid containing CMF as positive controls. To control for spontaneous maturation and the possible effects of ethanol in the arachidonic acid and ionophore treatments, oocytes were also incubated in ASW and $1 \%$ ethanol in ASW. To assess the effect of $\mathrm{pH}$ on maturation, ASW with a $\mathrm{pH}$ of 5.6, 7, 8, 9, 10, 11 and 12 (adjusted with either $1 \mathrm{M} \mathrm{HCl}$ or $1 \mathrm{M} \mathrm{NaOH}$ ) were all tested for maturation inducing activity. All chemicals, at the highest concentrations used, had a $\mathrm{pH}$ of between 7.0 and 7.6, except lanthanum chloride $(\mathrm{pH}$ of 5.6). ASW was determined to have a pH of 7.8. Tetracaine, procaine, propranolol, oxprenolol, lanthanum chloride, ionophore A23187, DL-dithiothreitol, arachidonic acid and ammonium ions (ammonium sulphate) were also all tested for their ability to induce maturation. The concentrations of all the chemicals used were $10^{-2}, 10^{-3}$ and $10^{-4} \mathrm{M}$, except for ionophore A23187 $\left(10^{-5}, 10^{-6}\right.$ and $\left.10^{-7} \mathrm{M}\right)$, arachidonic acid $\left(10^{-4}, 10^{-5}\right.$ and $\left.10^{-6} \mathrm{M}\right)$ and ammonium sulphate $\left(10^{-2}\right.$ and $\left.5 \times 10^{-2} \mathrm{M}\right)$. ASW with elevated $\mathrm{KCl}$ at concentrations of $2.6 \times 10^{-2}$, $5.4 \times 10^{-2}$ and $1.04 \times 10^{-1} \mathrm{M}$ and elevated calcium at concentrations of $6.8 \times 10^{-2}$ and $1.36 \times 10^{1} \mathrm{M}$ was also tested for maturation inducing activity as was calciumfree ASW made up according to Kuriyama et al. (1986). The maturation inducing ability of trypsin solution (1 and 3\% Type III bovine pancreas) was also tested. All chemicals were purchased from Sigma Chemical Co. except for propranolol which was purchased from ICN Biomedicals, Inc. 
Chemical induction of oocyte maturation in Arenicola defodiens. Oocytes from 2 donors were incubated in arachidonic acid and ionophore A23187 at concentrations of $10^{-5}$ and $10^{-6} \mathrm{M}$ for both chemicals and also $10^{-7} \mathrm{M}$ for arachidonic acid. As positive and negative controls, oocytes were incubated in femalc $A$. defodiens prostomial homogenate at a concentration of 0.5 prostomia $\mathrm{ml}^{-1}$ and ASW only respectively.

Statistical analysis. A Kolmogorov-Smimov 2-sample test was used to analyse the data on oocyte size frequencies (Fig. 1). To test for a significant difference in female fecundity between species (Fig. 2) a Student $t$-test was used to compare the regression coefficients for each regression line. For the results presented in. Figs. 3, 4 \& 5, differences between all treatments were analysed using an $\mathrm{R} \times \mathrm{C}$ test of independence using a $G$-test. Pairwise comparisons were then performed using Tukey-type multiple comparison tests for proportions.

\section{RESULTS}

\section{Observations on gametogenesis}

Frequency polygons of oocyte diameters for mature Arenicola defodiens and $A$. marina collected from Hauxley Haven are shown in Fig. 1. Oocytes of $A$. defodiens are fully grown but immature at a diameter of $159 \pm 0.46 \mu \mathrm{m}$ (mean \pm SEM) and are a dull brown in colour as opposed to $A$. marina which are fully grown

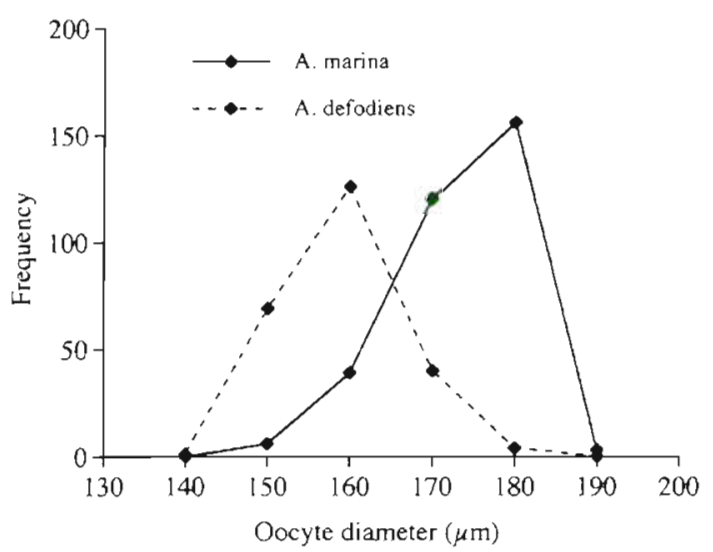

Fig. 1. Frequency polygon of mean oocyte diameters from 7 Arenicola marina and $5 \mathrm{~A}$. defodiens females (approximately 50 oocytes counted per female). All specimens were collected from sympatric populations at Hauxley Haven, Northumberland, UK. Data for Arenicola marina and A defodiens were from specimens collected on the 25 October and 20 December 1995, respectively. Both dates were just prior to the natural spawning of each population

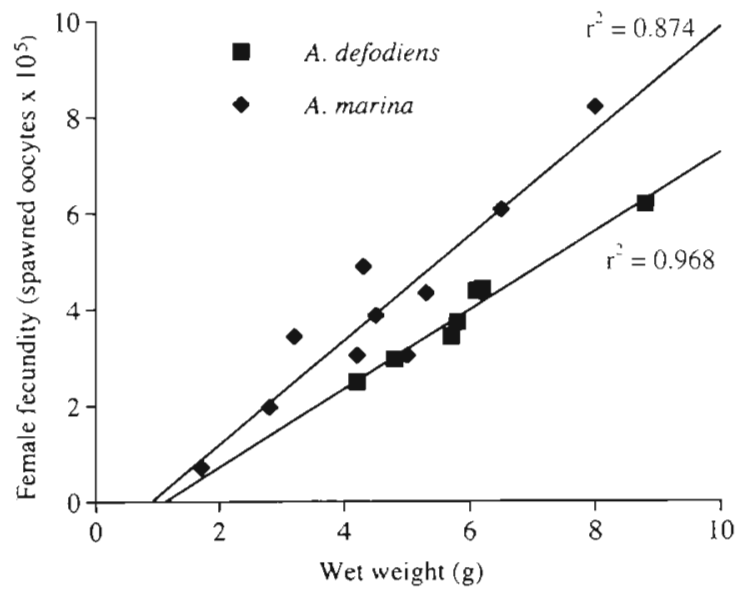

Fig. 2. Correlation between fecundity (total number of oocytes spawned $\times 10^{5}$ per female) and wet weight $(\mathrm{g})$ of females for Arenicola marina $(\mathrm{n}=10)$ and $A$. defodiens $(\mathrm{n}=7) \cdot\left(\mathrm{r}^{2}=0.968\right.$ for $A$. defodiens and $r^{2}=0.874$ for $A$. marina)

at $173 \pm 0.39 \mu \mathrm{m}$ and are bright orange. Statistical analysis shows that the distribution of fully grown oocytes of $A$. defodiens is significantly different from A. marina $(D=0.6778, \mathrm{p}<0.001)$.

The correlations between fecundity (number of eggs spawned $\times 10^{5}$ ) and wet weight (g) for females of each species is shown in Fig. 2. Results presented here show that as the wet weight of specimens of both species increases there is an increase in the total number of oocytes spawned $\left(\mathrm{r}^{2}=0.968\right.$ and 0.874 for Arenicola defodiens and $A$. marina, respectively). However, the increase in fecundity, corrected for body weight, for $A$. defodiens is significantly lower when compared to $A$. marina $(t=3.482, \mathrm{p}=0.05)$.

\section{Observations on the spawning of natural populations}

At sites where both species exist sympatrically, for example at West Sands, St Andrews (E. Scotland), Arenicola marina spawn in late October or early November at spring tides (the peak of spawning in 1997 was from the 30 October to the 2 November). A. defodiens from that site, however, were still mature approximately 1 mo later after the $A$. marina population had spawned, although the exact date of spawning was not recorded. At Hauxley Haven in 1995, A. marina spawned on the spring tides of the week beginning 30 October with sympatric $A$. defodiens spawning on the week beginning 15 January 1996. Other populations of $A$. defodiens also spawn much later in the year, with a population from Sand Head on the West Coast of Scotland spawning around the 1 February 1996. 


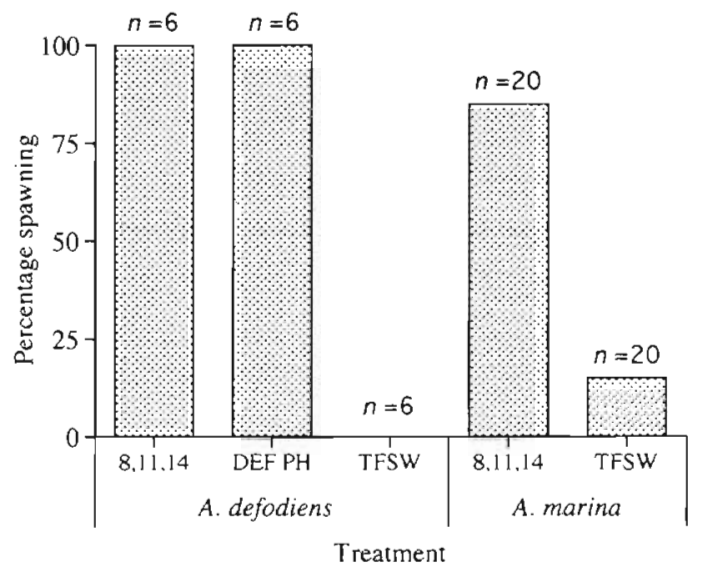

Fig. 3. Percentage spawning response of male Arenicola marina and $A$. defodiens to various treatments. $8,11,14$ : injection of 8,11,14-eicosatrienoic acid to give a final concentration of $13 \mu \mathrm{g} \mathrm{g}^{-1}$ body mass; DEF PH: injection with male $A$. defodiens prostomial homogenate to give a final concentration of 1 prostomium equivalent per male; TFSW: injection of $200 \mu \mathrm{l}$ twice filtered seawater. All specimens were left for $12 \mathrm{~h}$ at $10^{\circ} \mathrm{C}$ before being assessed for spawning. $n$ is the number of individuals in each treatment group

\section{Induction of spawning of males with $8,11,14$ - eicosatrienoic acid}

The induction of spawning in male Arenicola defodiens and $A$. marina with $8,11,14$-eicosatrienoic acid is shown in Fig. 3. Statistical analysis using an $\mathrm{R} \times \mathrm{C}$ test of independence using a $G$-test shows that highly significant differences $\left.\alpha^{2}=42.57, \mathrm{p}<0.001\right)$ exist between all treatments. The injection of $8,11,14$ eicosatrienoic acid induced $100 \%$ of the $A$. defodiens and $85 \%$ of the $A$. marina to spawn. Statistical analysis of pairwise comparisons using a modified Tukey test shows that the injection of 8,11,14-eicosatrienoic acid induces highly significant levels of spawning in both species $(q=6.032, p<0.001$ for $A$. defodiens and $q=$ $6.01, \mathrm{p}<0.001$ for $A$. marina) when compared to their respective controls. The injection of male $A$. defodiens prostomial homogenate also induced highly significant levels $(q=6.032, p<0.001)$ of spawning in $A$. defodiens $(100 \%)$. No significant differences exist when these 3 treatments are compared $(q=3.858 p>0.05)$. None of the seawater injected $A$. defodiens and only $15 \%$ of $A$. marina spawned spontaneously.

\section{Reciprocal induction of spawning in females}

The spawning in females of both species can be induced by either Arenicola marina or $A$. defodiens female prostomial homogenate (Fig. 4). In 1997, the injection of $A$. defodiens with either species' prosto-

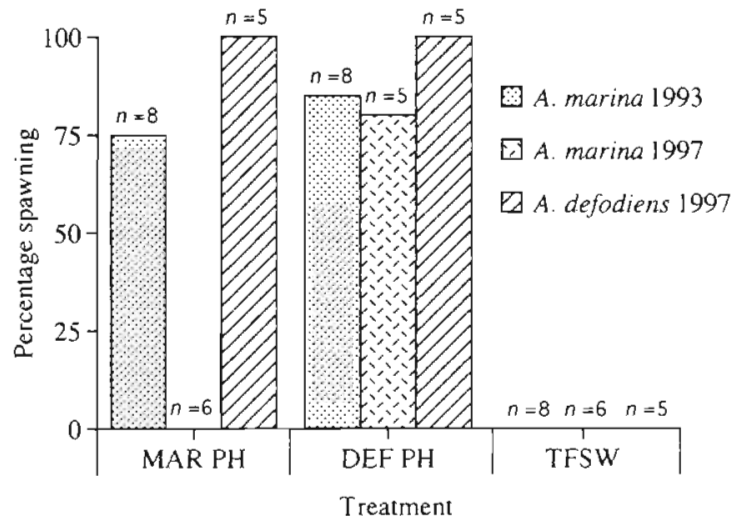

Fig. 4. Percentage spawning response of female Arenicola marina in 1993 and 1997 and A. defodiens 1997 after injection with various treatments. DEF PH: injection with female $A$. defodiens prostomial homogenate to give a final concentration of 1 prostomium equivalent per female; MAR PH: injection with female $A$. defodiens prostomial homogenate to give a final concentration of 1 prostomium equivalent per female; TFSW: injection of $200 \mu l$ twice filtered seawater. All specimens were left for $12 \mathrm{~h}$ at $10^{\circ} \mathrm{C}$ before being assessed for spawning. $n$ is the number of individuals in each treatment group

mial homogenate induced $100 \%$ of each treatment group to spawn. Of the $A$. marina injected with $A$. defodiens prostomial homogenate, spawning was induced in 85 (1993) and $80 \%$ (1997) of the specimens. In $1993,75 \%$ of the A. marina injected with A. marina prostomial homogenate spawned; however, in 1997 the repeat experiment resulted in none of the $A$. marina spawning. No females of either species injected with TFSW spawned.

Statistical analysis of the data, as performed previously, shows that highly significant differences are present between all treatments $\left.\alpha^{2}=26.124, p<0.001\right)$, Pairwise comparisons of these differences confirm that a significant level of spawning is induced by all treatments, when compared to their respective controls (TFSW injected), except for $A$. marina injected with $A$. marina prostomial homogenate in 1997 ( $q=0.11$, $p>$ $0.05)$. No significant differences $(p>0.05)$ are present between pairwise comparisons of the treatments that induce significant spawning.

\section{In vitro induction of oocyte maturation}

The in vitro induction of oocyte maturation in both species by incubation in prostomial homogenate and $\mathrm{CMF}$ is shown in Fig. 5. Statistical analysis using an $\mathrm{R}$ $\times C$ test of independence using a $G$-test shows that highly significant differences exist between all treatments $\left.\alpha^{2}=2509.2, p<0.001\right)$. Subsequent pairwise comparisons using the modified Tukey test show that 
significant maturation of Arenicola marina oocytes, when compared with controls and other treatments, occurred only when they were incubated in coelomic fluid containing CMF. The levels of maturation achieved in the different females' coelomic fluid were not significantly different from each other except for coelomic fluid Sample 1, which was significantly higher than all other coelomic fluid samples. Incubation of $A$. marina oocytes in prostomial homogenate of either species up to a concentration of 10 prostomia $\mathrm{ml}^{-1}$ for $A$. marina and 5 prostomia $\mathrm{ml}^{-1}$ for $A$. defodiens failed to induce any significant maturation when compared to the control. In contrast, pairwise comparisons show that oocytes of $A$. defodiens underwent very significant levels of maturation (mean value of $90 \%$ ) when incubated in a range of concentrations of prostomial homogenate of either species or in the coelomic fluid containing CMF. Pairwise comparisons also show that there is no significant difference in the number of $A$. defodiens oocytes maturing when incubated in either species' prostomial homogenate. There is no significant maturation of oocytes from either species when incubated in the seawater control.

\section{Chemical induction of oocyte maturation}

Maturation of each species' oocytes only occurred when they were incubated in their respective positive controls. For Arenicola marina $79 \%$ of the oocytes matured in coelomic fluid with CMF activity, while $100 \%$ of $A$. defodiens' oocytes matured when incubated in female $A$. defodiens prostomial homogenate at a concentration of 0.5 prostomia $\mathrm{ml}^{-1}$. All the following treatments, at all concentrations tested and incubated for either 2 or $4 \mathrm{~h}$, failed to induce any maturation of oocytes of $A$. marina: tetracaine, procaine, propranolol, oxprenolol, lanthanum chloride and DL-dithiothreitol $\left(10^{-3}, 10^{-4}\right.$ and $\left.10^{-5} \mathrm{M}\right)$, ionophore A23187 $\left(10^{-5}, 10^{-6}\right.$ and $\left.10^{-7} \mathrm{M}\right)$, arachidonic acid $\left(10^{-4}, 10^{-5}\right.$ and $\left.10^{-6} \mathrm{M}\right)$, ammonium sulphate $\left(10^{-2}\right.$ and $\left.5 \times 10^{-2} \mathrm{M}\right), \mathrm{KCl}$ enriched ASW $(2.6 \times$ $10^{-2}, 5.4 \times 10^{-2}$ and $\left.1.04 \times 10^{-1} \mathrm{M}\right)$, calcium enriched ASW $\left(6.8 \times 10^{-2}\right.$ and $\left.1.36 \times 10^{-1} \mathrm{M}\right)$, trypsin $(1$ and $3 \%$ solutions of Type III bovine pancreas), ASW (pH adjusted to $5.6,7,8,9,10,11$ and 12), calcium free ASW, ASW only and ASW with $1 \%$ ethanol. The following treatments also failed to induce any maturation in $A$. defodiens oocytes: ionophore A23187 $\left(10^{-5}\right.$ and $\left.10^{-6} \mathrm{M}\right)$, arachidonic acid $\left(10^{-5}, 10^{-6}\right.$ and $\left.10^{-7} \mathrm{M}\right)$ and ASW only.
A. marina $\square$ A. defodiens

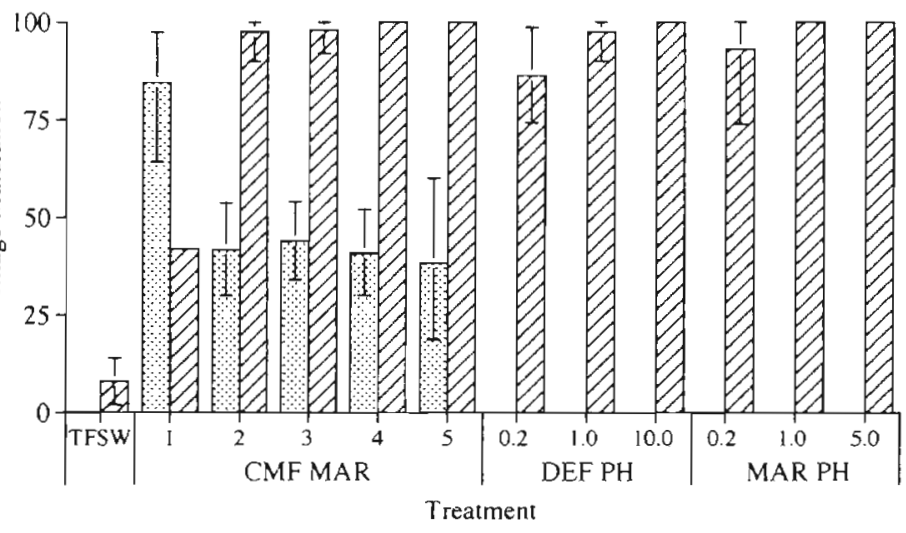

Fig. 5. Maturation response of oncytes of Arenicola marina and A. defodiens incubated in various treatments. TFSW: TFSW only; CMF MAR 1, 3, 4, 5: coelomic fluids from 5 female $A$. marina containing $C M F$ MAR PH: prostomial homogenate of A. marina at concentrations of 0.2 , and 10 prostomial $\mathrm{ml}^{-1}$; DEF PH: prostomial homogenate of $A$. defodiens at concentrations of $0.2,1$ and 5 proslomial $\mathrm{ml}^{-1}$. Response expressed as arcsine back-transformed mean percentage $( \pm S E M)$ of oocytes matured

\section{DISCUSSION}

Arenicola marina and $A$. defodiens can be separated by a variety of ecological, morphological and genetic criteria (Cadman \& Nelson-Smith 1990, 1993, Cadman 1997). However, until now, no direct comparisons or experiments have been undertaken to examine whether these differences extend to the reproductive biology of the 2 species. Observations described here have confirmed that the reproductive biology of these 2 species, at least in females, is different. Vitellogenesis in A. marina begins in mid-June and results in the production of fully-grown (approximately $175 \mu \mathrm{m}$ diameter) but immature oocytes (Howie 1961). In contrast oocytes of $A$. defodiens are smaller (160 $\mu$ m diameter) and a different colour (dull brown as opposed to bright orange). Fecundity of females of $A$. defodiens is also lower when compared to similarly sized $A$. marina. Results presented in Fig. 2 show that as females increase in size, fecundity of $A$. defodiens increases at a slower rate than that of $A$. marina. It is likely that a similar situation exists in males, although these data were not recorded. The lower levels of fecundity in $A$. defodiens compared to $A$. marina may be related to the reduced available coelomic fluid volume for developing oocytes and sperm. This lower available volume of the coelomic cavity for gamete development is probably due to the thicker body wall of $A$. defodiens (authors' pers. obs.).

Reproductive differences between the species have also been shown to extend to the population level. Most UK populations of Arenicola marina spawn in autumn or early winter (Howie 1959, Duncan 1960, 
Williams et al. 1997). Observations from sites around the UK indicate that the timing of spawning of $A$. defodiens is approximately 1 to 2 mo later than sympatric A. marina. The observed spawning of A. marina at sites such as West Sands and Hauxley Haven is highly synchronised and is restricted to 2 or 3 days in the year (Bentley \& Pacey 1992, Williams et al 1997, G. J. Watson pers. obs.); however, there have been no observations of spawning in the field of $A$. defodiens. It is unknown, therefore, whether $A$. defodiens exhibits the same level of within-population synchronisation as $A$. marina. Similarly, the spawning behaviour of $A$. defodiens in the field has not been observed. Although personal observations of males in the laboratory suggest that they spawn with less muscular contractions than A. marina, the method of spawning has not be recorded. What is clear is that the reproductive seasons are significantly separated in time to prevent cross fertilization (artificial cross fertilizations have so far not produced viable larvae; P. S. Cadman pers. obs.)

Arenicola marina and $A$. defodiens are clearly different in their reproductive biology. In particular there are subtle differences in the hormonal control of spawning. Results presented above have shown that both sexes from both species share certain common elements of control as well as exhibiting fundamental differences. Males of both species can be induced to spawn with the injection into the coelomic cavity of 8,11,14-eicosatrienoic acid, which has already been putatively identified as the spawning inducer and SMF for A. marina (Bentley et al. 1990, Pacey \& Bentley 1992a). To conclude, however, that in males, the system of sperm maturation and spawning is identical in both species would be premature. Results obtained with females (see below for discussion) show that 2 systems may contain similar or identical components, but, upon further examination, are different. Clearly, 8,11,14-eicosatrienoic acid plays an important role in sperm activation and spawning in $A$. defodiens, although its exact role is unknown.

The injection of female Arenicola marina prostomial homogenate into the coelomic cavity of female $A$. marina is now a reliable endocrine technique to induce spawning of ripe females (Howie 1961, Pacey \& Bentley $1992 \mathrm{a}$, Watson \& Bentley 1997, 1998b). The results shown in Fig. 4, however, show that, although $75 \%$ of the 1993 females spawned, all the 1997 A. marina failed to spawn after injection. This was unexpected, but one possible explanation for the failure to spawn relates to the titres of PMH present within the $A$. marina prostomial homogenate and the threshold concentration of $\mathrm{PMH}$ required to induce spawning in females. Previous work (Watson 1996) has shown that in A. marina the nearer to the natural spawning time of a population you inject females with prostomial homogenate, the greater the number of females will spawn. This could be because as the natural spawning approaches the levels of PMH within the prostomium increases concurrently with the receptivity of females to spawn (a possible decrease in threshold level required for $\mathrm{PMH}$ ). The $A$. defodiens used in the 1997 experiments may have been closer to spawning spontaneously than the $A$. marina and therefore higher levels of PMH would have been present in their homogenate and they would also have been more receptive to injection (had lower $\mathrm{PMH}$ thresholds) compared to the $A$. marina. Consequently, when the $A$. marina were injected with both species' homogenates the $A$. defodiens homogenate induced them to spawn due to the higher levels of $\mathrm{PMH}$ in the homogenate exceeding the threshold levels of the A. marina. The lower levels of $\mathrm{PMH}$ in the $A$. marina homogenate would have failed to reach the higher threshold level required by the $A$. marina, resulting in a failure to spawn. However, because there would be enough PMH present in the A. marina homogenate to exceed the lower threshold level of PMH required in the $A$. defodiens, all of the $A$. defodiens injected with $A$. marina prostomial homogenate were induced to spawn.

The results of the in vitro experiments (Fig. 5), confirming our earlier work (Watson \& Bentley 1997), show that Arenicola marina oocytes will undergo maturation only in coelomic fluid containing $\mathrm{CMF}$. The presence of this substance is essential for oocytes of $A$. marina to mature, but oocytes of $A$. defodiens require only the presence of PMH (from either species). In $A$. defodiens, CMF is not produced, and oocyte maturation only requires the presence of $\mathrm{PMH}$. In $A$. marina, $\mathrm{PMH}$ is also essential but is the first of 2 steps, with CMF as a second substance which then acts on the oocyte to induce maturation.

A comparison of the control of reproduction and oocyte maturation in these 2 species with other systems, for example the asteroid echinoderms, demonstrates a unique level of interspecific control of oocyte maturation. In all of the asteroids so far studied, oocyte maturation and spawning is under the control of a 2step hormonal system. This involves the production of a Gonad Stimulating Substance (GSS) which in turn induces the production of the meiosis inducing substance (MIS), 1-methyladenine, from the follicle cells which induces spawning and oocyte maturation (for review, see Meijer \& Mordet 1994). This system has therefore been conserved across all species of asteroids so far investigated. In molluscs there is also evidence, from a number of species of bivalves, that neurotransmitters, in particular serotonin, are involved in the control of reproduction (Matsutani \& Nomura 1982, 1986, Gibbons \& Castagna 1984, Hirai et al. 1988, Ram 
et al. 1993). In polychaetes, it seems that many more systems have evolved in the control of reproduction. (see for example the diversity of pheromones involved in nereid spawning [Zeeck et al. 1988, 1990, 1991. Hardege et al. 1991]) with the different systems of oocyte maturation in Arenicola marina and $A$. defodiens being an extreme example.

At the level of the oocyte, the system of maturation also appears different. Meijer (1980) suggested that, because maturation in Arenicola defodiens could be induced by chemicals affecting intracellular calcium levels (tetracaine, procaine, propranolol, oxprenolol, verapamil and lanthanum chloride), calcium plays a key role in the maturation process in this species. The results presented here show that in A. manina, elevation of intracellular calcium, specifically caused by these chemicals, does not alone induce maturation. The failure of any of these chemicals to induce maturation is in contrast to results for $A$. defodiens (Meijer 1980). However, the results presented here are consistent with some work on starfish: increases in intracellular calcium do occur during maturation but they are not a requirement for maturation, or sufficient to induce maturation themselves (Kikuyama \& Hiramoto 1991). Further work to examine the exact role of calcium and whether it is essential for oocyte maturation in starfish has provided contradictory results. An increase in calcium in the nucleus, although not in the cytoplasm, is essential for maturation in starfish (Santella \& Kyozuka 1994). Other conflicting results on the role of calcium are the lack of maturation in oocytes of starfish and $A$. defodiens when exposed to ionophore A23187, whereas the oocytes of other species such as Spisula solidissima and Pectinaria gouldii mature in its presence (Schuetz 1975, Anstrom \& Summers 1981). It has been suggested that in starfish the surge of calcium induced by the ionophore A.23187 is too large (20 times greater than the calcium increase due to 1 methyladenine) and outside the limits required to induce maturation (Moreau et al. 1978).

The failure of oocytes to mature when incubated with DTT DL-dithiothreritol suggests that the reduction of disulphide bonds also does not play a significant part in the process of maturation in Arenicola marina. These findings contrast with the maturation process of both $A$. defodiens and starfish, in which DTT and another disulphide reducing agent (2,3-dimercaptoethanol) induce significant maturation (Kishimoto \& Kanatani 1973, Meijer 1980).

The complete failure of Arenicola marina oocytes to mature in all of the test chemicals is in contrast to the situation found not only in $A$. defodiens but also starfish and many other species. An increase in pH of seawater has been shown to induce maturation in the molluscs Patella vulgata (Guerrier et al. 1986) and Cellana nigrolineata (Catalan \& Yamamoto 1993), suggesting that internal $\mathrm{pH}$ changes may play a role in the maturation of oocytes of these species. In Nereis virens and Spisula spp., oocytes undergo maturation when external $\mathrm{KCl}$ and calcium are elevated, supporting a role for the opening of calcium channels in the oocyte membrane (Heilbrunn \& Wilbur 1937, Allen 1953). In starfish, Meijer et al. (1984), showed that arachidonic acid and related compounds can induce oocyte maturation, suggesting that these may also play a role within the oocyte. In the hydrozoan, Phialidium greganium, oocyte maturation can be induced by calcium ionophore A23187 and ammonia, also suggesting a role of calcium and intracellular $\mathrm{pH}$ changes in oocyte maturation in the cnidarians (Freeman \& Ridgway 1993).

The results presented here demonstrate that in Arenicola marina the mechanism of oocyte maturation, specifically the transduction of the CMF signal to the activation of MPF, is different to that of $A$. defodiens, and may also be different to the other more extensively studied systems of other species described already. The chemicals and treatments tested here fail to induce maturation because (1) they have no essential role in oocyte maturation so that changes induced are irrelevant; (2) they induce too little or too much change in the oocyte to induce maturation; and (3) they may be acting, in this case, in a different way to their reported pharmacological action. Further studies on $A$. marina investigating the internal changes in pathways such as calcium and $\mathrm{pH}$ with microinjection and other tech-

Table 1. Summary of the endocrine control or spawning and oocyte maturation in females of Arenicola marina and A. defodiens. PMH: Prostomial Maturation Hormone; CMF: Coelomic Maturation Factor

\begin{tabular}{|c|c|c|c|c|c|}
\hline Species & $\begin{array}{l}\text { Hormonal } \\
\text { step } 1\end{array}$ & $\begin{array}{l}\text { Hormonal } \\
\text { step } 2\end{array}$ & Effect on oocyte & $\begin{array}{l}\text { Requirement } \\
\quad \text { for } \mathrm{Ca}^{2+}\end{array}$ & $\begin{array}{l}\text { Requirement } \\
\text { tor disulphide } \\
\text { bond reduction }\end{array}$ \\
\hline Arenicola marina & $\begin{array}{c}\mathrm{PMH} \text { (A. marina or } \\
\text { A. defodiens) }\end{array}$ & $\mathrm{CMF}$ & $\begin{array}{l}\text { Maturdtion from prophase } \\
\text { to metaphase of meiosis I }\end{array}$ & No & No \\
\hline Arenicola defodiens & $\begin{array}{c}\text { PMH (A. marina or } \\
\text { A. defodiens) }\end{array}$ & - & $\begin{array}{l}\text { Maturation from prophase } \\
\text { to metaphase of meiosis I }\end{array}$ & Yes & Yes \\
\hline
\end{tabular}


niques are required to ascertain the role of these chemical pathways in the maturation of the oocytes.

The results presented in this paper show for the first time that differences between Arenicola marina and $A$. defodiens also extend to the reproductive biology, timing of spawning and specific elements of the endocrine control of oocyte maturation. A summary diagram of the endocrine control of reproduction in females of both species is shown in Table 1 . Clearly such fundamental differences between closely related species have evolutionary implications in relation to the ecological niche occupied by each species. However, it is clear from Table 1 that all aspects of both species' reproductive biology warrant further investigation.

Acknowledgements. The authors thank Seabait Ltd for providing specimens and for access to their facilities. The authors also acknowledge the support of NERC grant GR3/10521 to M.G.B.

\section{LITERATURE CITED}

Allen RD (1953) Fertilization and artificial activation in the egg of the surf clam, Spisula solidissima. Biol Bull 105: 213-237

Anstrom J, Summers RG (1981) The role of extracellular $\mathrm{Ca}^{2+}$ in the activation of Pectinaria oocytes. Dev Growth Differ 23:415-420

Baloun AJ, Morse DE (1984) Ionic control of settlement and metamorphosis in larval Haliotis rufescens (Gastropoda). Biol Bull 167:124-138

Bentley MG (1985) Sperm maturation response in Arenicola marina $\mathrm{L}$ : in vitro assay for sperm maturation factor and its partial purification. Int $J$ Invertebr Reprod Dev 8: 139-148

Bentley MG, Hardege JD (1996) The role of a fatty acid hormone in the reproduction of the polychaete Arenicola marina (L.). Invertebr Reprod Dev 30:159-165

Bentley MG, Pacey AA (1992) Physiological and environmental control of reproduction in polychaetes. Oceanogr Mar Biol Annu Rev 30:443-481

Bentley MG, Clark S, Pacey AA (1990) The role of arachidonic acid and eicosatrienoic acids in the activation of spermatozoa in Arenicola marina (L.) (Annelida: Polychaeta). Biol Bull 178:1-9

Beukema JJ, de Vlas J (1979) Population parameters of the lugworm, Arenicola marina, living on tidal flats in the Dutch Wadden Sea. Neth J Sea Res 13:457-478

Cadman PS (1997) Distribution of two species of lugworm (Arenicola) (Annelida: Polychaeta) in South Wales. J Mar Biol Assoc UK 77:389-398

Cadman PS, Nelson-Smith A (1990) Genetic evidence for two species of lugworm (Arenicola) in South Wales. Mar Ecol Prog Ser 64:107-112

Cadman PS, Nelson-Smith A (1993) A new species of lugworm: Arenicola defodiens sp. nov. J Mar Biol Assoc UK 73:213-223

Catalan MAB, Yamamoto $\mathrm{M}$ (1993) The effect of $\mathrm{pH}$ on meiosis reinitiation in oocytes of the prosobranch mollusc Cellana nigrolineata (Reeves). Invertebr Reprod Dev 23: $211-213$

Duncan A (1960) The spawning of Arenicola marina (L.) in the British Isles. Proc Zool Soc Lond 134:137-156
Farke H, Berghuis EM (1979) Spawning, larval development and migration of Arenicola marina under field conditions in the western Wadden Sea. Neth J Sea Res 13: $529-535$

Farke H, DeWilde PAWJ, Berghuis EM (1979) Distribution of juvenile and adult Arenicola marina on a tidal mud-flat and the importance of the nearshore for recruitment. Neth $J$ Sea Res 13:354-361

Freeman G, Ridgeway RL (1993) The role of intracellular calcium and $\mathrm{pH}$ during fertilization and egg activation in the hydrozoan Phialidium. Dev Biol 156:176-190

Gamble FW, Ashworth JH (1898) The habits and structure of Arenicola marina (L.). Q J Microsc Sci 41:1-42

Gibbons MC. Castagna M (1984) Serotonin as an inducer of spawning in six bivalve species. Aquaculture 40:189-191

Guerrier P, Brassart M, David C, Moreau M (1986) Sequential control of meiosis reinitiation by $\mathrm{pH}$ and $\mathrm{Ca}^{2+}$ in oocytes of the prosobranch mollusc Patella vulgata. Dev Biol 116: $315-324$

Hardege JD, Bartels-Hardege $H$, Zeeck E (1991) Volatile compounds from the coelomic fluid of Nereis succinea: biological activity as sex pheromones. Invertebr Reprod Dev 19:83-85

Heilbrunn LV, Wilbur KM (1937) Stimulation and nuclear breakdown in the Nereis egg. Biol Bull 73:557-564

Hirai S, Kishimoto T, Kadman AL, Kanatani H, Koide SS (1988) Induction of spawning and oocyte maturation by 5hydroxytryptamine in the surf clam. I Exp Zool 245: 318-321

Howie DID (1959) The spawning of Arenicola marina (L.). I. The breeding season. J Mar Biol Assoc UK 38:395-406

Howie DID (1961) The spawning of Arenicola marina (L.). III. Maturation and shedding of the ova. J Mar Biol Assoc UK 41:771-783

Howie DID (1963) Experimental evidence for the humoral stimulation and ripening of the gametes and spawning in the polychaete Arenicola marina (L.). Gen Comp Endocrinol 3:660-668

Howie DID (1966) Further data relating to the maturation hormone and its site of secretion in Arenicola marina (L.). Gen Comp Endocrinol 6:347-361

Kikuyama Mi Hiramato Y (1991) Change in intracellular calcium ions upon maturation in starfish oocytes. Dev Growth Differ 33:533-638

Kishimoto T, Kanatani H (1973) Induction of starfish oocyte maturation by disulphide-reducing agents. Exp Cell Res 82:296-302

Kuriyama R, Borisy GG, Masui Y (1986) Microtubule cycles in oocytes of the surf clam, Spisula solidissima: an immunofluorescence study. Dev Biol 114.151-160

Matsutani T, Nomura T (1982) Induction of spawning by serotonin in the scallop, patinopecten yessoensis (Jay). Mar Biol Lett 3:353-358

Matsutani T, Nomura T (1986) Pharmacological observations on the mechanism of spawning in the scallop Patinopecten yessoensis. Bull Jpn Soc Sci Fish 52:1589-1594

Meijer L (1979a) Hormonal control of oocyte maturation in Arenicola marina L. (Annelida, Polychaeta). I. Morphological study of oocyte maturation. Dev Growth Differ 21: 303-314

Meijer L (1979b) Hormonal control of oocyte maturation in Arenicola marina L. (Annelida, Polychaeta). Il. Maturation and fertilization. Dev Growth Differ 21:315-329

Meijer L (1980) Hormonal control of oocyte maturation in Arenicola marina L. (Annelida, Polychaeta). III. Involvement of $\mathrm{Ca}^{2+}$ and -SH groups in meiosis reinitiation. Dev Growth Differ 22:33-38 
Meijer L, Durchon M (1977) Contrôle neurohormonal de la maturation ovocytaire chez Arenicola marina (Annélide Polychète). Etude in vitro. C R Acad Sci Paris 285:377-380

Meijer L, Guerrier P, Maclouf J (1984) Arachidonic acid, 12 and 15-hydroxyeicosatetraenoic acids, eicosapentaenoic acid, and phospholipase $A_{2}$ induce starfish oocyte maturation. Dev Biol 106:368-378

Meijer M, Mordet G (1994) Starfish oocyte maturation: from prophase to metaphase. Semin Dev Biol 5:165-171

Moreau M, Guerrier P, Dorée M, Ashley CC (1978) Hormoneinduced release of intracellular $\mathrm{Ca}^{2+}$ triggers meiosis in starfish oocytes. vature 272:251-252

Pacey AA, Bentley MG (1992a) The fatty acid 8,11,14eicosatrienoic acid induces spawning in the male lugworm Arenicola marina. J Exp Biol 173:165-179

Pacey AA, Bentley MG (1992b) An ultrastructural study of spermatogenesis and sperm morula breakdown in Arenicola marina (L.) (Annelida: Polychaeta). Helgol Meeresunters 46:185-199

Ram JL, Crawford GW, Walker JU, Mojares JJ, Patel N, Fong PP, Kyozuka K (1993) Spawning in the zebra mussel (Dreissena polymorpha): activation by internal or external application of serotonin. J Exp Zool 265:587-598

Santella L, Kyozuka K (1994) Reinitiation of meiosis in starfish oocytes requires an increase in nuclear $\mathrm{Ca}^{2+}$. Biochem Biophys Res Commun 203:674-680

Schuetz AW (1975) Induction of nuclear breakdown and meiosis in Spisula solidissima oocytes by calcium ionophore. J Exp Zool 191:433-440

Watson GJ (1996) Oocyte maturation, fertilization and post-

Editorial responsibility: Otto Kinne (Editor),

Oldendorf/Luhe, Germany fertilization development in two polychaete species. PhD thesis, University of St Andrews

Watson GJ, Bentley MG (1997) Evidence for a coelomic maturation factor controlling oocyte maturation in the polychaete Arenicola marina (L.). Invertebr Reprod Dev 31 297-306

Watson GJ, Bentley MG (1998a) Oocyte maturation and postfertilization development of Arenicola marina (L.) (Annelida: Polychaeta). Invertebr Reprod Dev 33:35-46

Watson GJ, Bentley MG (1998b) Action of CMF (Coelomic Maturation Factor) on oocytes of the polychaete Arenicola marina (L.). J Exp Zool 281:65-71

Wells GP (1963) Barriers and speciation in lugworms (Arenicolidae, Polychaeta). In: Harding JP, Tebble N (eds) Speciation in the sea. London Systematics Association, London, p 79-98

Williams ME, Bentley MG, Hardege JD (1997) Assessment of field fertilization success in the infaunal polychaete Arenicola marina (L.). Invertebr Reprod Dev 31:189-197

Zeeck E, Hardege J, Bartels-Hardege H, Wesslmann G (1988) Sex pheromone in a marine polychaete: determination of the chemical structure. J Exp Zool 246:285-292

Zeeck E, Hardege J, Bartels-Hardege H (1990) Sex pheromones and reproductive isolation in two nereid species, Nereis succinea and Platynereis dumerilii. Mar Ecol Prog Ser 67:183-188

Zeeck $E$, Hardege J, Bartels-Hardege $H$, Willig A, Wesselmann G (1991) Sex pheromones in a marine polychaete: active compounds from female Platynereis dumerilii. J Exp Zool 260:93-98

Submitted: June 9, 1998; Accepted: September 16, 1998

Proofs received from author(s): November 30, 1998 